\title{
Modal Analysis of Micro and Nanowires Using Finite Element Softwares
}

\author{
Kadir Mercan ${ }^{a}$, Ömer Civalek ${ }^{b^{*}}$ \\ Department of Civil Engineering, Faculty of Engineering, Akdeniz University, Antalya, TURKIYE \\ *E-mail address: civalek@yahoo.com \\ ORCID numbers of authors: \\ 0000-0003-3657-6274, $0000-0003-1907-9479^{b}$
}

Received date: 23.12 .2018

Accepted date: 15.02 .2019

\begin{abstract}
The aim of this work is to represent a quick and truthful modality to obtain frequencies of microwires and nanowires which are widely used in nanosensors, nanocircuit and many more susceptible scientific areas. In this paper, modal analysis of micro and nano sized wires is investigated using COMSOL software. To obtain first ten mode shapes and eigenfrequencies of silicon carbide nanowire, thirty-nine modes is calculated. Results are given in figures captured from the software.
\end{abstract}

Keywords: Modal analysis, microwires, nanowires, SiCNW, COMSOL.

\section{Introduction}

As experimental analyzes of very small structures like carbon nanotubes (CNT), silicon carbide nanotubes (SiCNT), boron nitride nanotubes (BNNT), zinc oxide nanotube $(\mathrm{ZnO})$ and nanowires of homologous structures is very-high costed and take a long time, many methods have been developed to make analysis possible without any experiment. Similarly, atomic simulation and molecular dynamic analysis need too much time to analyze nanotubes in case of buckling and vibration. Continuum mechanics models have been widely used to perform modal, dynamic and stability analysis using mathematical model [1-4]. Computer softwares have also been widely used to perform modal, dynamic and stability analysis in recent years [58]. Most of analysis softwares is not able to model structures in micro and nano size. Determining the critical buckling loads and frequencies of nanotubes is very important in case of designing for its particular using areas.

Finite element method (FEM) is a very time-effective method if meshing phase is done properly. This method has been used for a very wide range of analysis. Many different geometries can be modeled using the method such as very complex parts of engineering systems [9-15], beams, plates [16], shells [17, 18], human body parts such as kidney, bone etc. [19-22]. The computer software used to obtain mode shapes and eigenfrequencies is a finite element method based software. 


\section{Modelling Structures}

Meshing is the most important part of software analyzes [23]. Inaccurate meshing leads to inaccurate results in modal, dynamic, and stability analyzes. For example, coarse meshing as it can be seen In Fig. 1 (a) would end up with improper results for current model. On the other hand, too fine meshing (Fig. 1 (c)) would end up with accurate and close results to experiments however analyzes would take very long time due to very much calculating vertexes in body.

a)

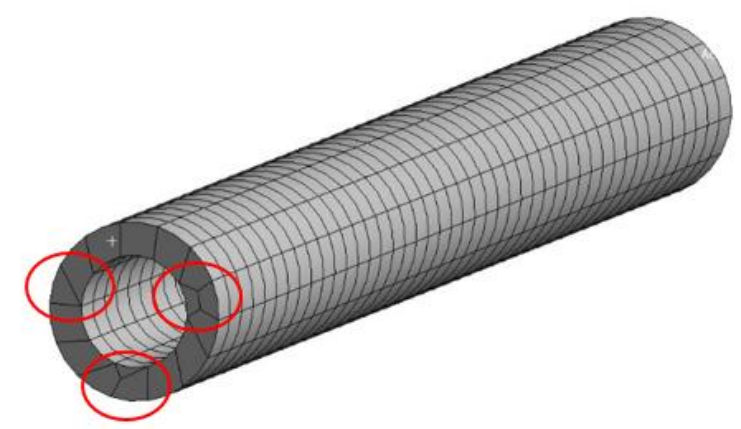

c)

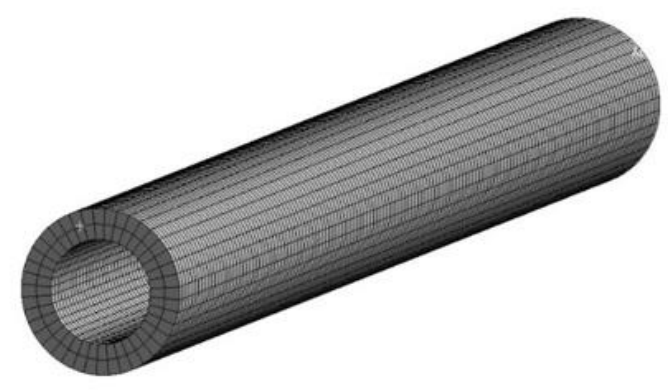

b)

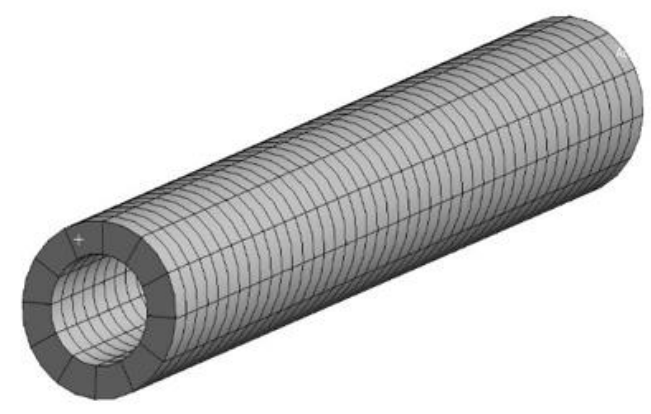

d)

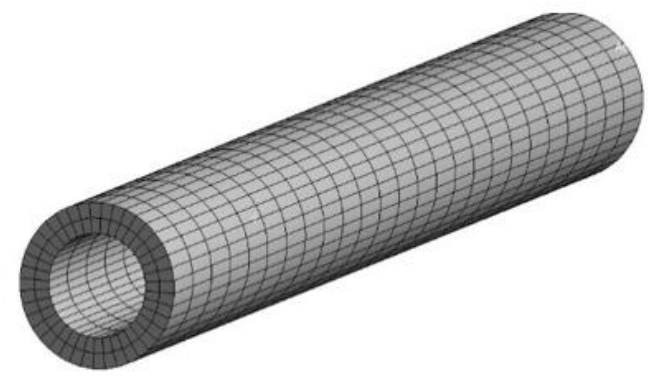

Fig. 1. Meshing nanostructures

Ideal meshing steps of a modeled nanotube is demonstrated in Fig. 1. respectively. In first step, skewed and irregular links between vertexes is observed and demonstrated in red circles (Fig. 1(a)). After fixing this issue (Fig. 1. (b)) it is observed that none of vertex were placed throughout the thickness of nanotube, this issue would lead to inaccurate results due to none of calculation throughout the thickness of nanotube. To overcome this issue, the spacing between vertexes is reduced (Fig. 1 (c)). As it can be seen in Fig. 1 (c). As it is stated before, too fine meshing would take very long time of analyzes due to very much calculating vertexes in body. Spacing between vertexes is extended for the body while reduced spacing is preserved along the thickness of nanostructure (Fig. 1 (d)). 


\section{Modal Analysis of SiCNW}

COMSOL Multiphysics [24] is used to model and perform modal analysis on selected silicon carbide nanowire ( $\mathrm{SiCNW}$ ). Subsequent to meshing, needed material properties (Young's modulus 0.62 TPa and Poisson ratio 0.37) and geometrical properties is defined [25, 26]. Eventually, intended boundary conditions is defined (simply support in this case).

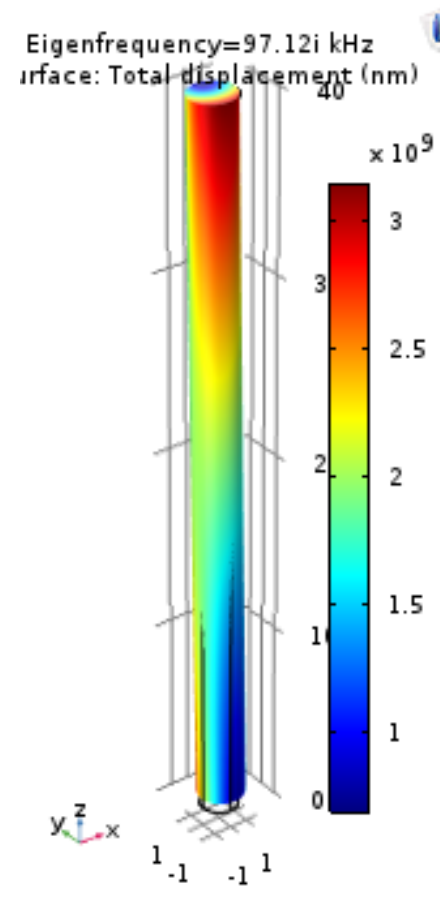

Mode 1

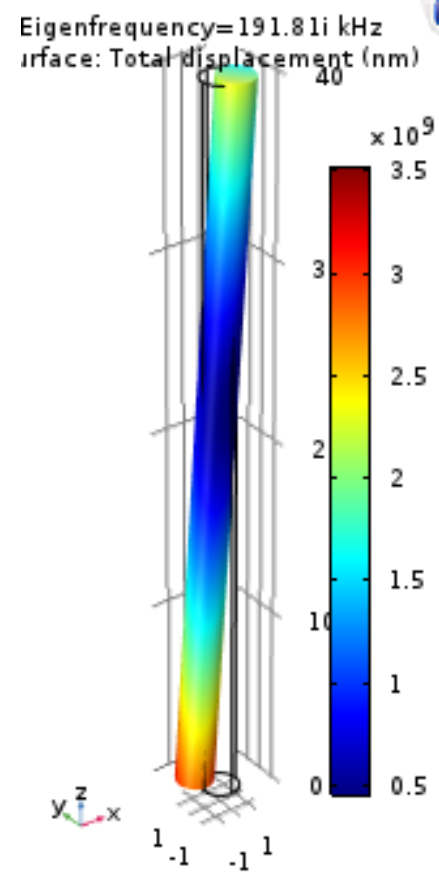

Mode 2
Eigenfrequency $=340.99 \mathrm{iHz}$ Irface: Total displacement (nm)

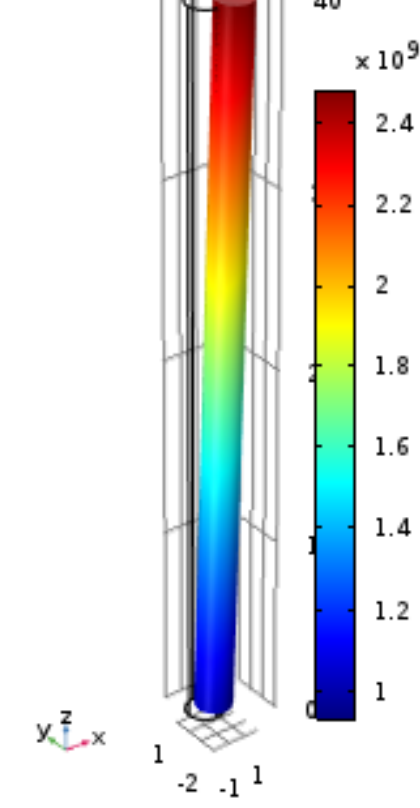

Mode 3

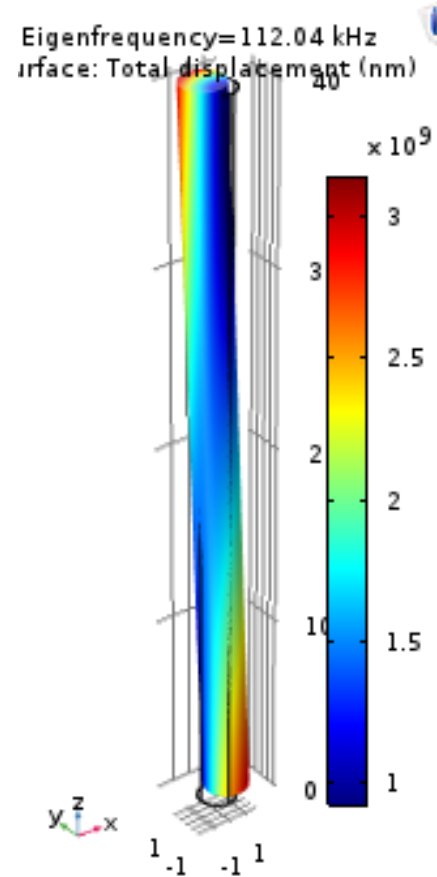

Mode 4

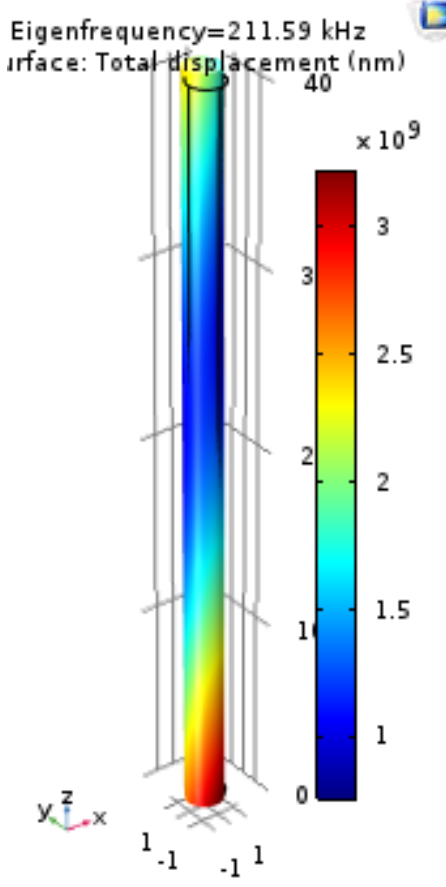

Mode 5

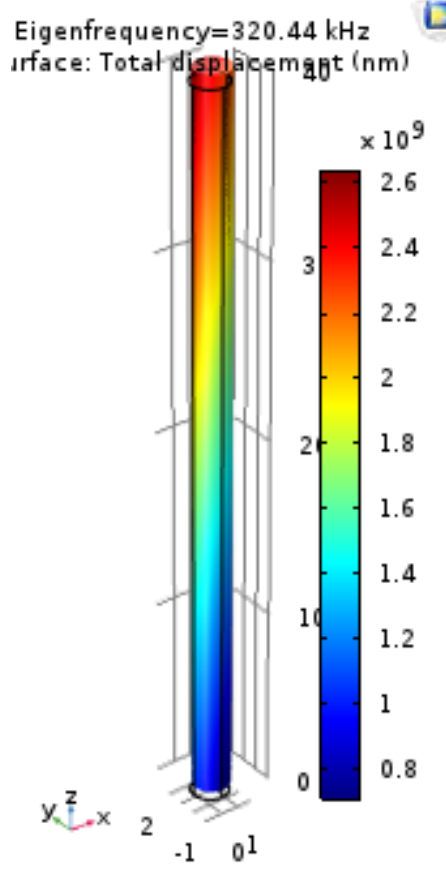

Mode 6 


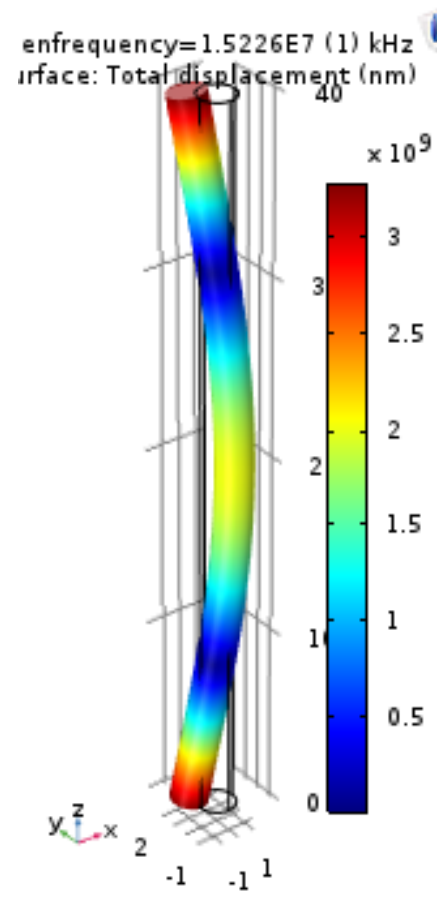

Mode 7

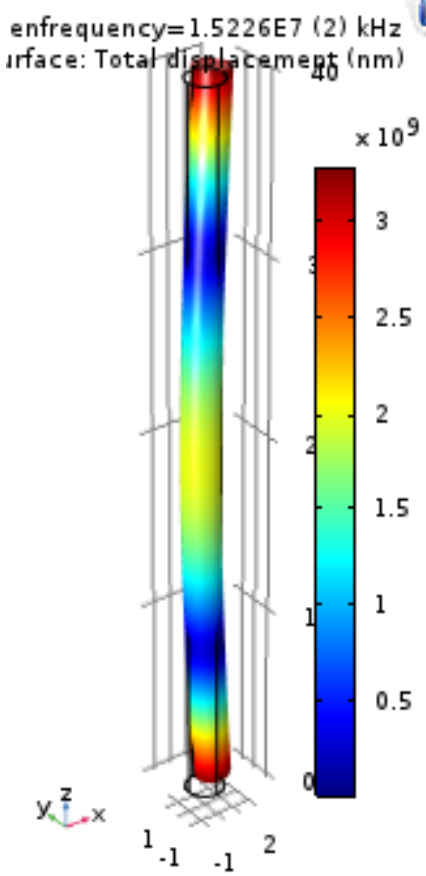

Mode 8
enfrequency=4.1476E7 (1) kHz $\square$ IIface: Total displacement $(\mathrm{nm})$

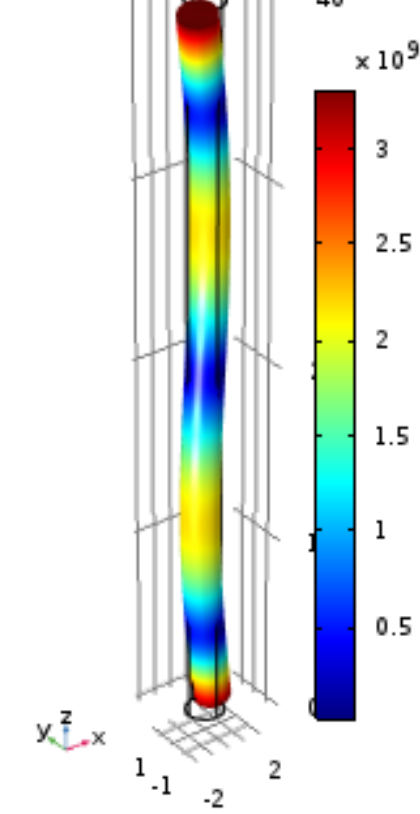

Mode 9

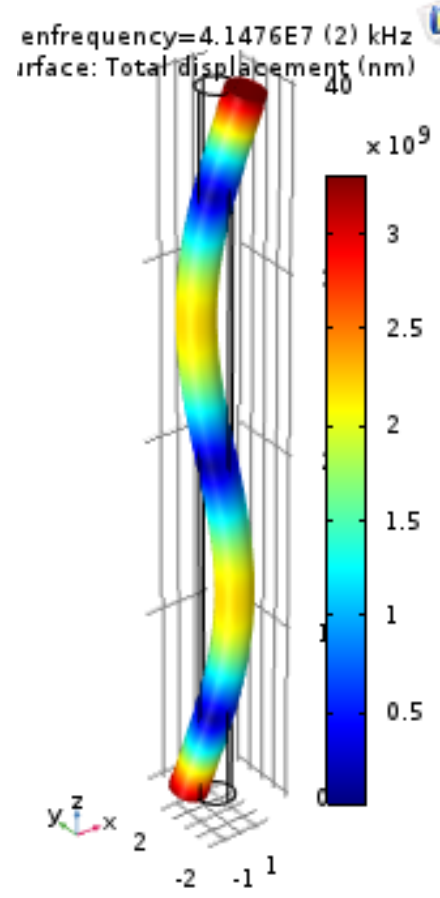

Mode 10

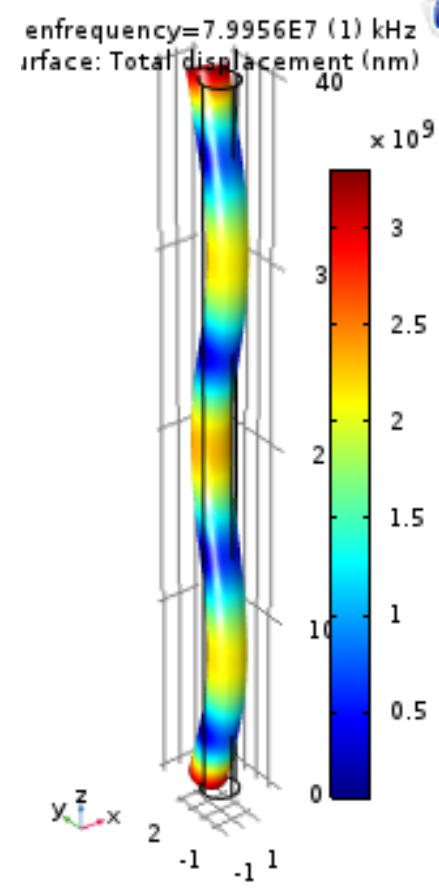

Mode 11

\section{口}

enfrequency=7.9956E 7 (2) $\mathrm{kHz}$ IIface: Total dischlaćements $(\mathrm{nm})$

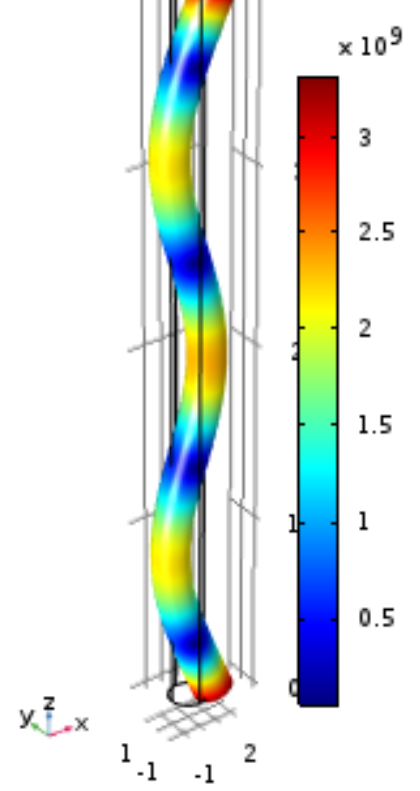

Mode 12 


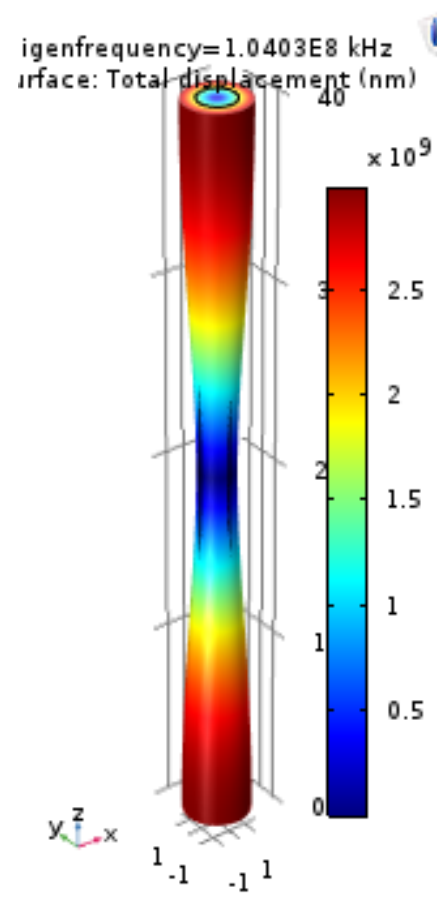

Mode 13

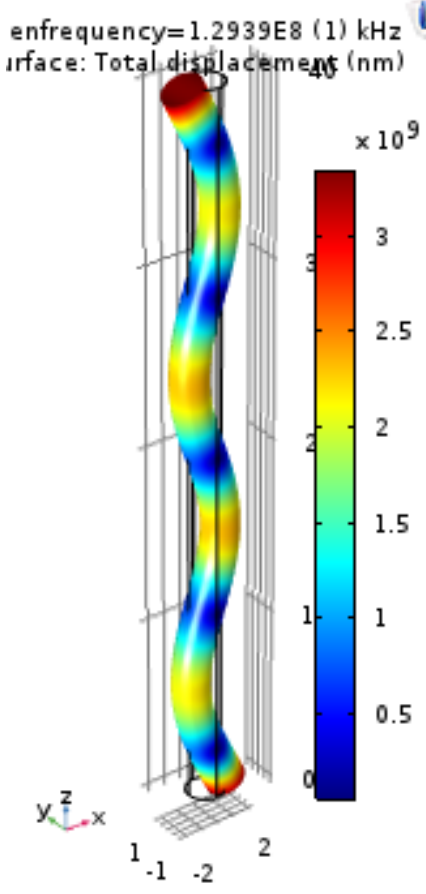

Mode 14 enfrequency $=1.2939 \mathrm{E} 8$ (2) $\mathrm{kHz} \square$ Irface: Totat displacement (nm)

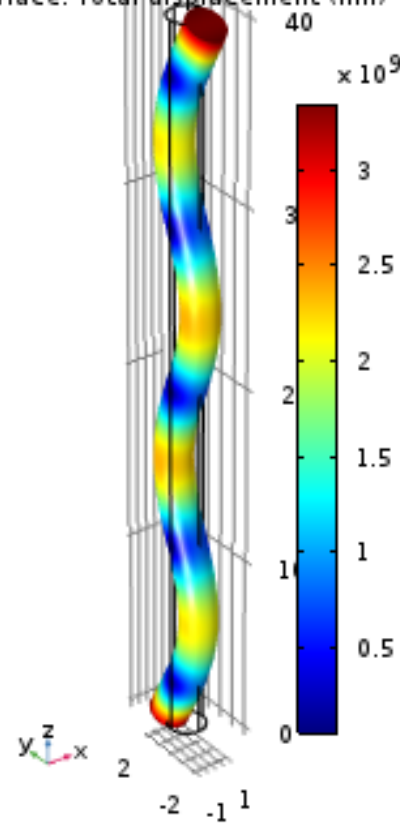

Mode 15

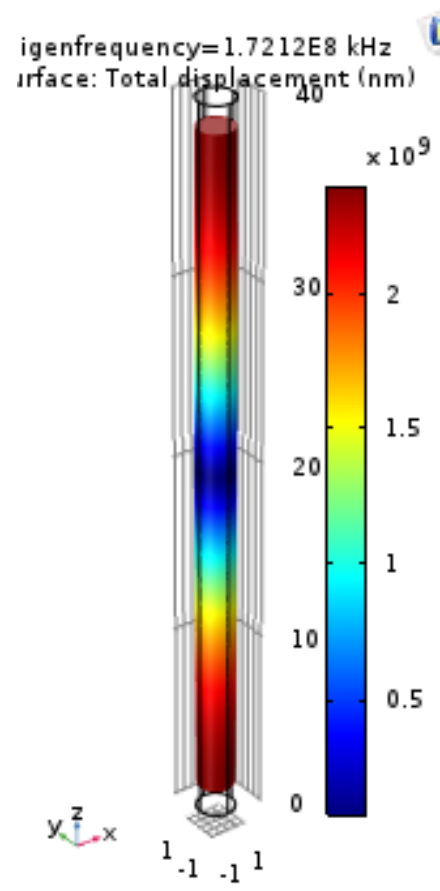

Mode 16

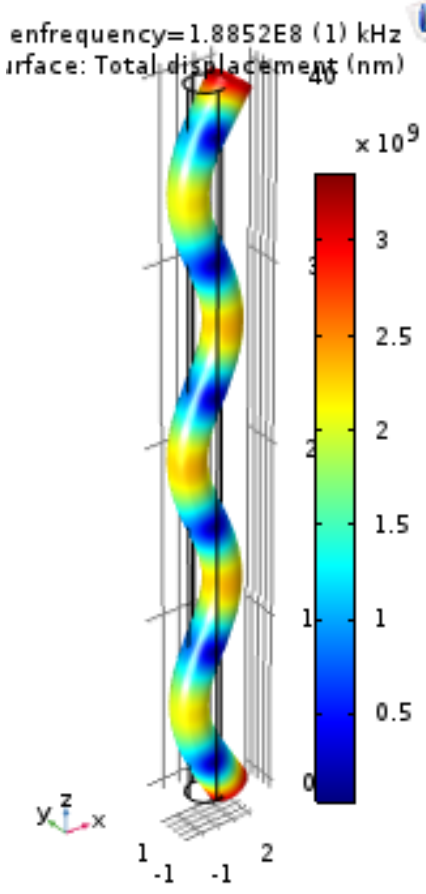

Mode 17

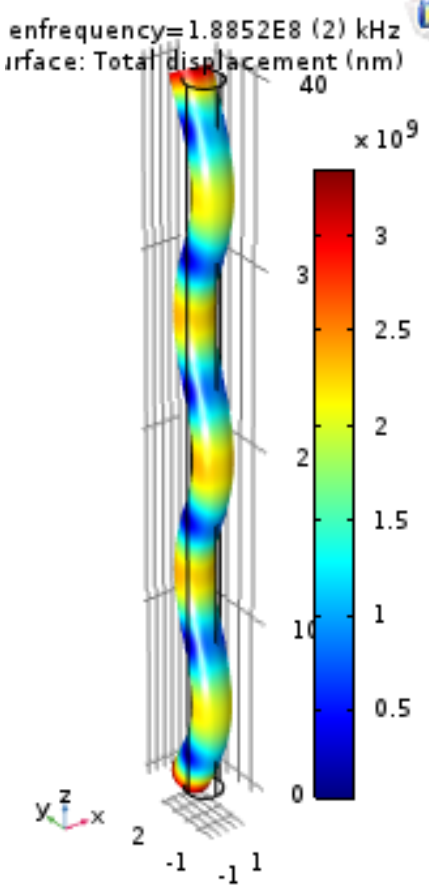

Mode 18 


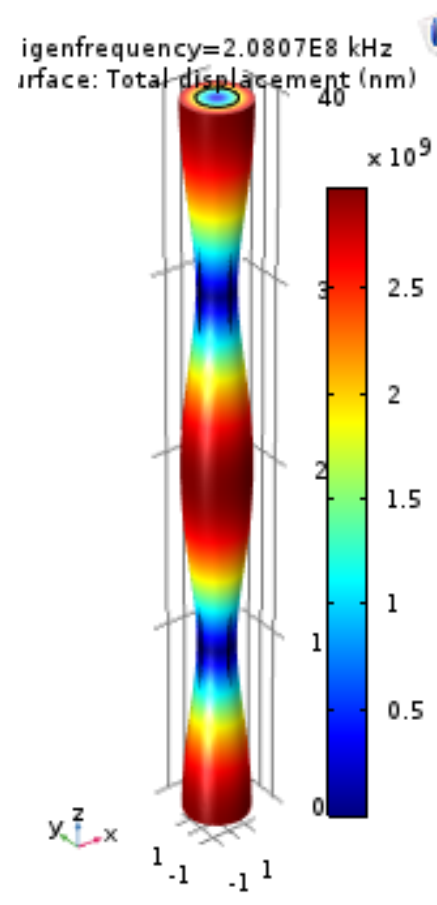

Mode 19

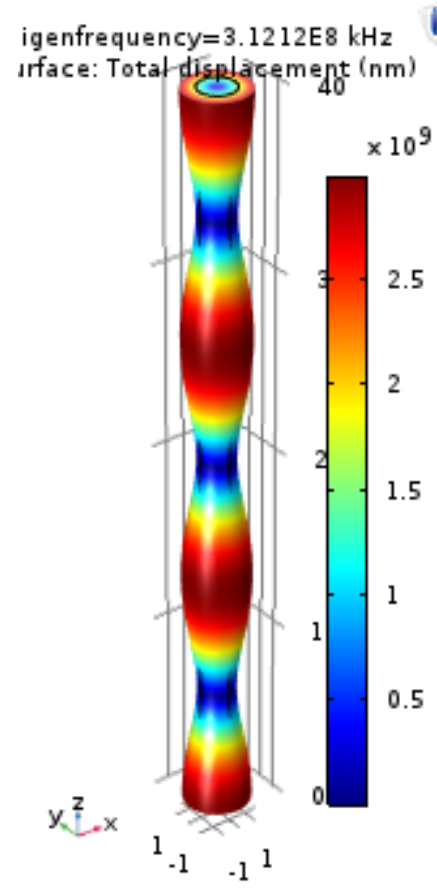

Mode 22

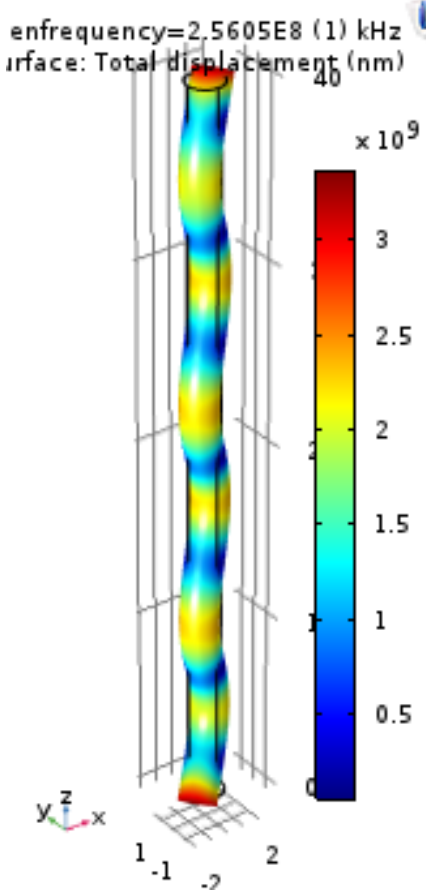

Mode 20 enfrequency $=2.5605 \mathrm{E8}$ (2) $\mathrm{kHz}$ Irface: Totat displacement $(\mathrm{nm})$

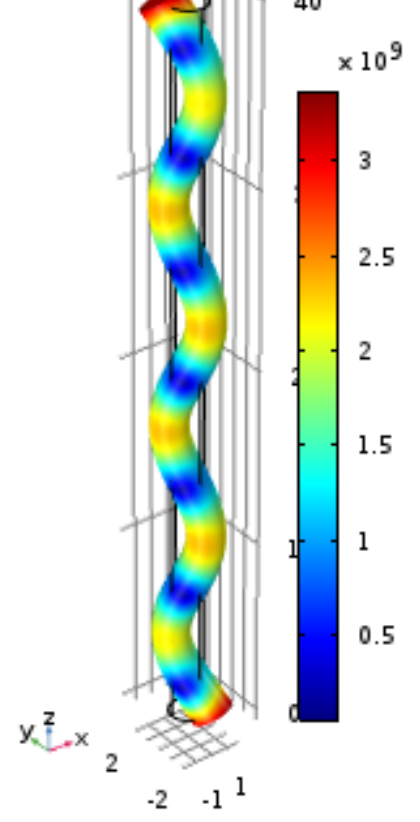

Mode 21

1 igenfrequency $=3.3074 \mathrm{E} 8 \mathrm{kHz}$ Irface: Total displacement $(\mathrm{nm})$

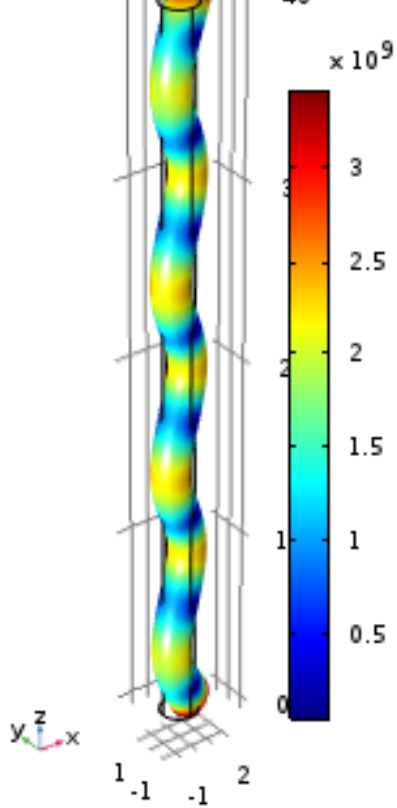

Mode 23 igenfrequency $=3.3075 \mathrm{E} 8 \mathrm{kHz}$ Ifface: Total displacement $(\mathrm{nm})$ ace. Total 40

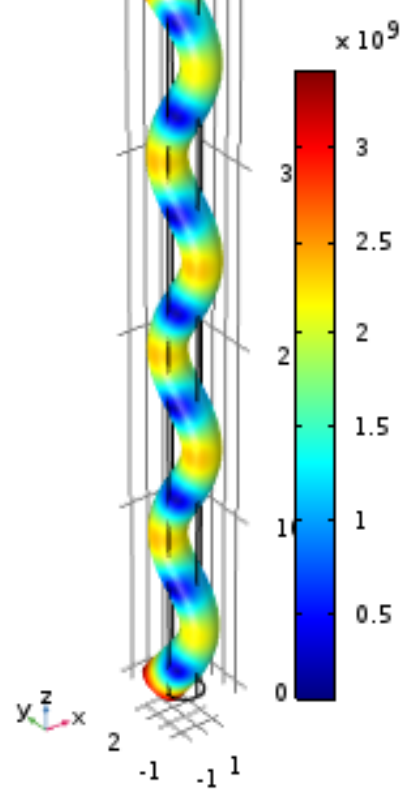

Mode 24 


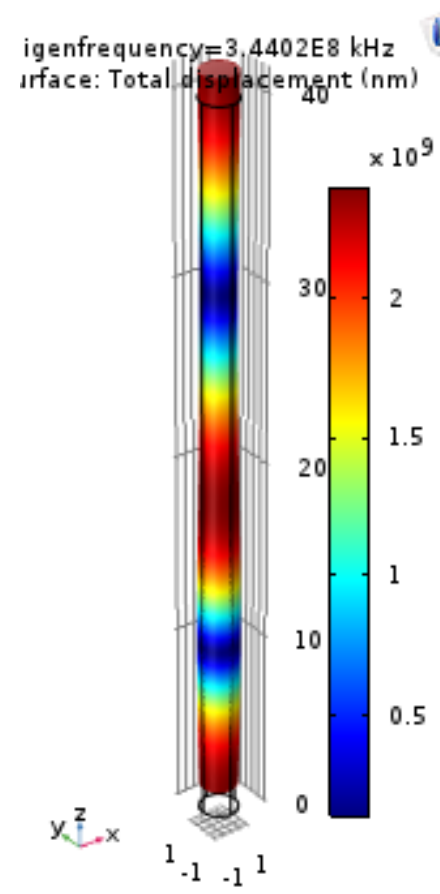

Mode 25

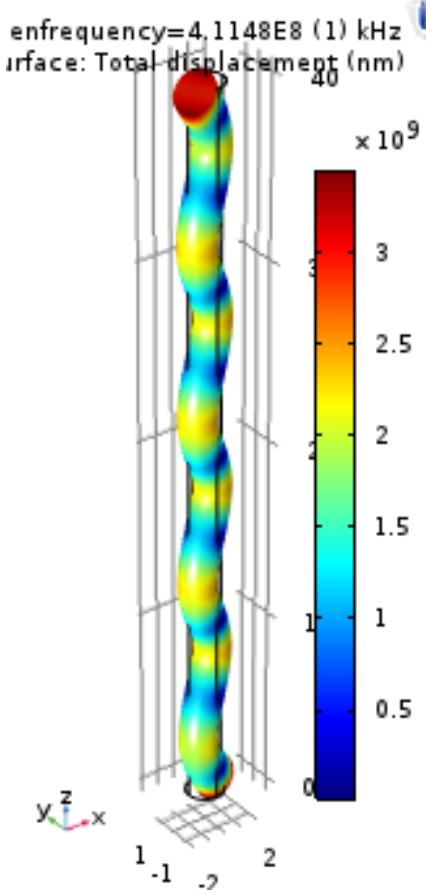

Mode 26 enfrequency $=4.1148 \mathrm{E} 8$ (2) $\mathrm{kHz}$ Irface: Total displacement $(\mathrm{nm})$

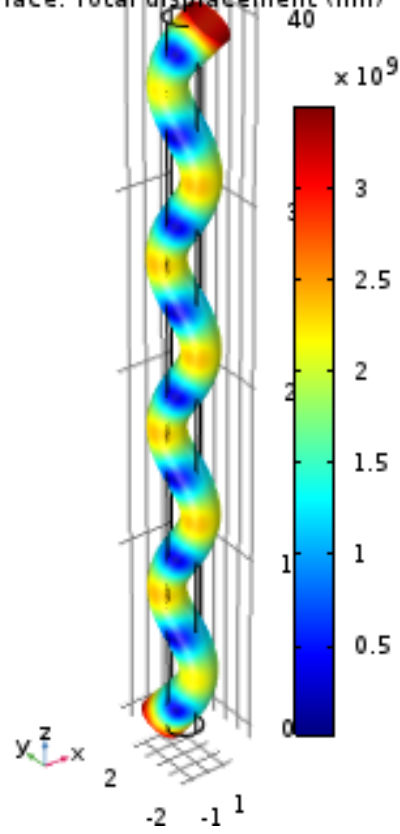

Mode 27

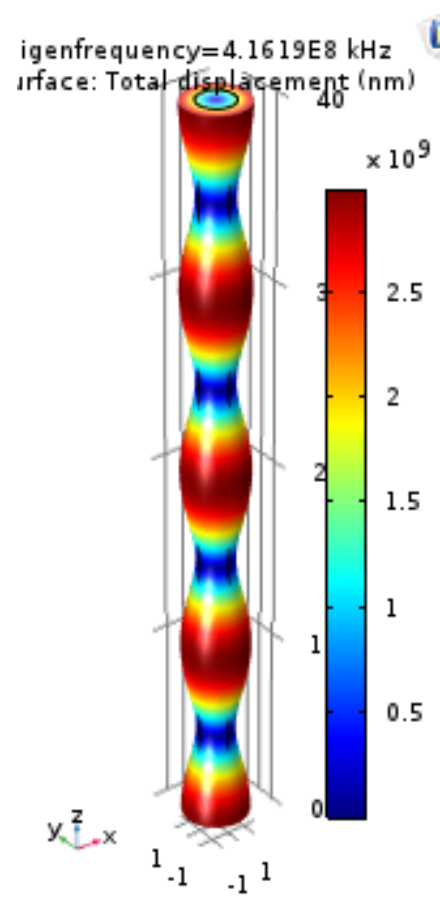

Mode 28

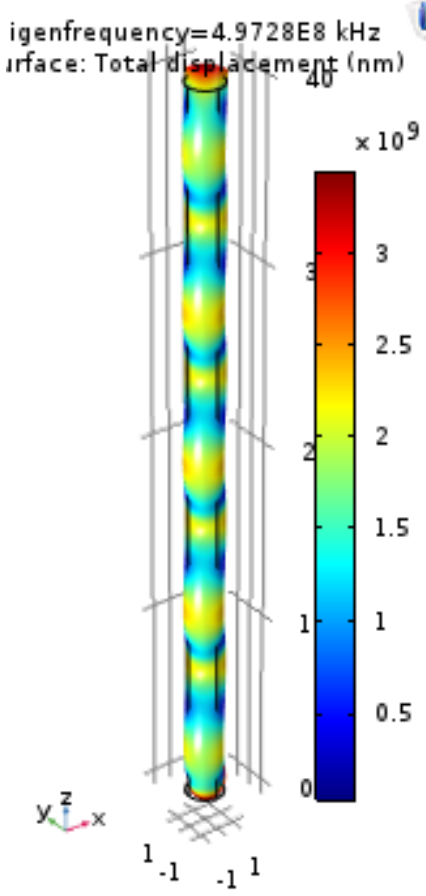

Mode 29

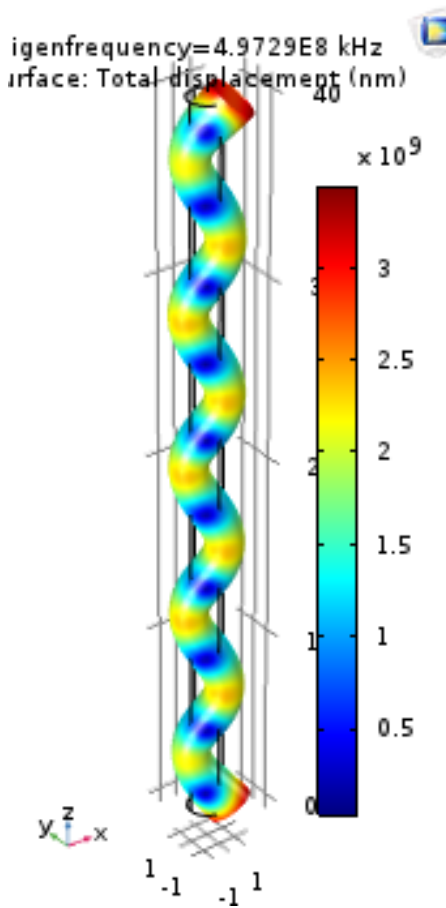

Mode 30 


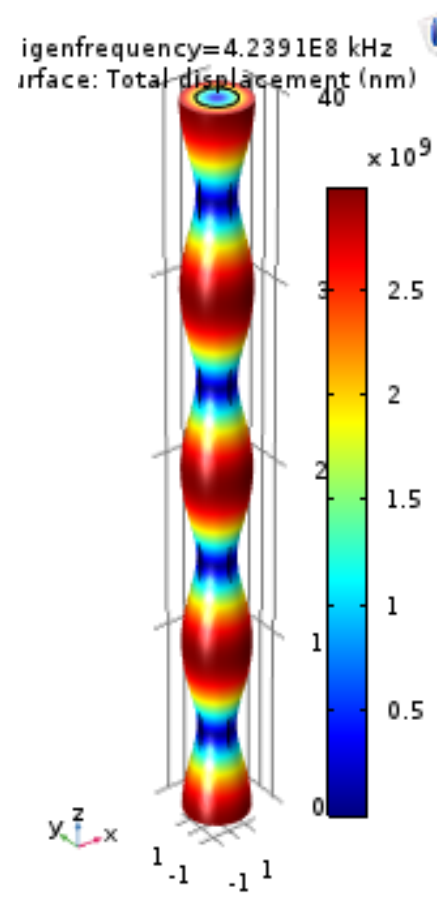

Mode 31

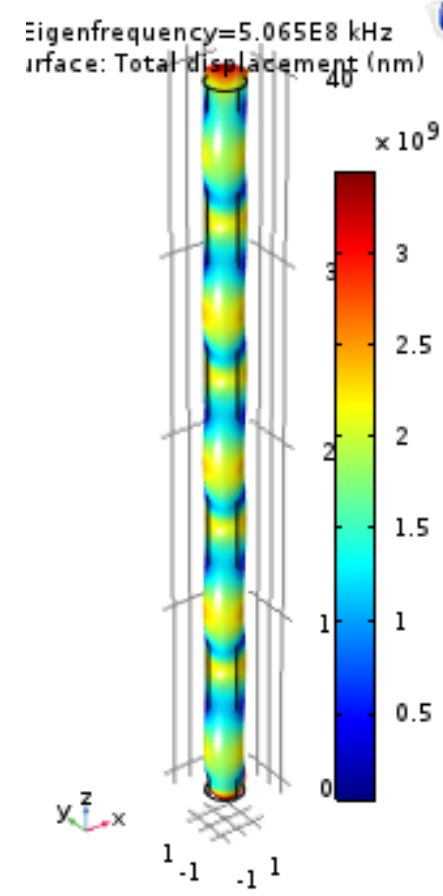

Mode 32 igenfrequency $=5.0651 \mathrm{E} \mathrm{kHz}$
Ifface: Total displadement $(\mathrm{nm})$

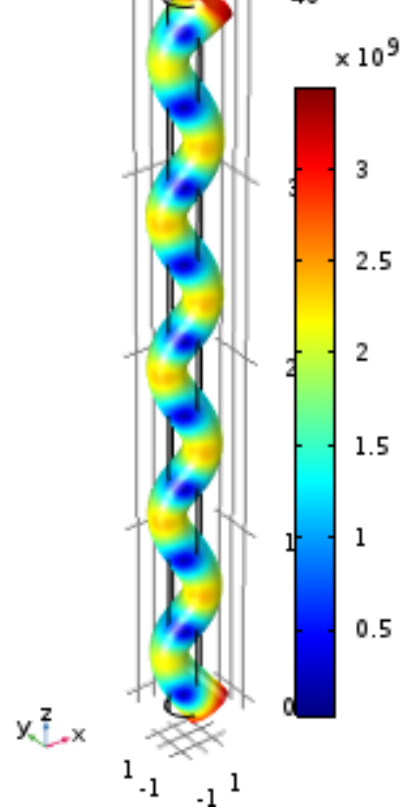

Mode 33

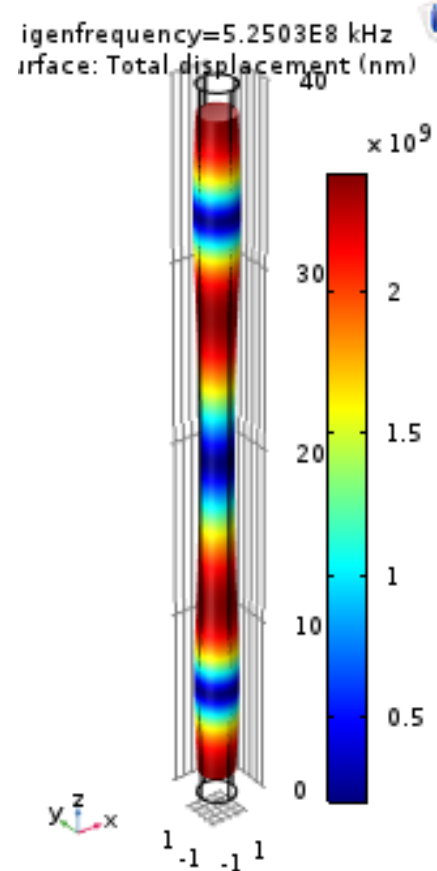

Mode 34

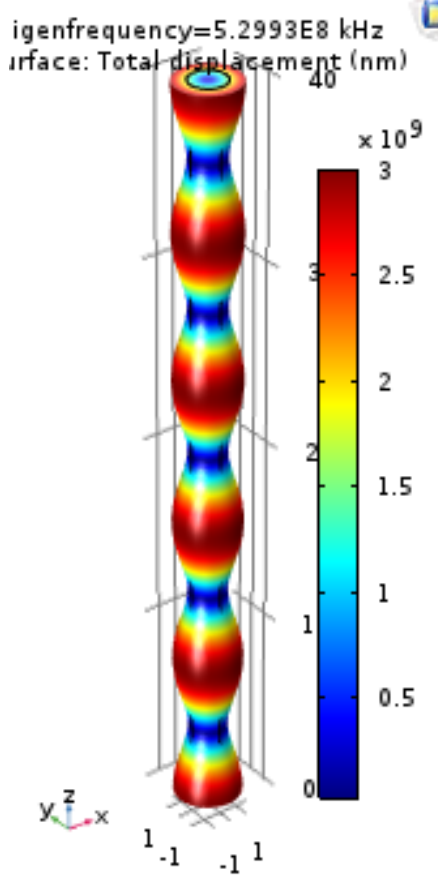

Mode 35 igenfrequency $=5.9814 \mathrm{E} 8 \mathrm{kHz}$ Irface: Total displacement $(\mathrm{nm})$

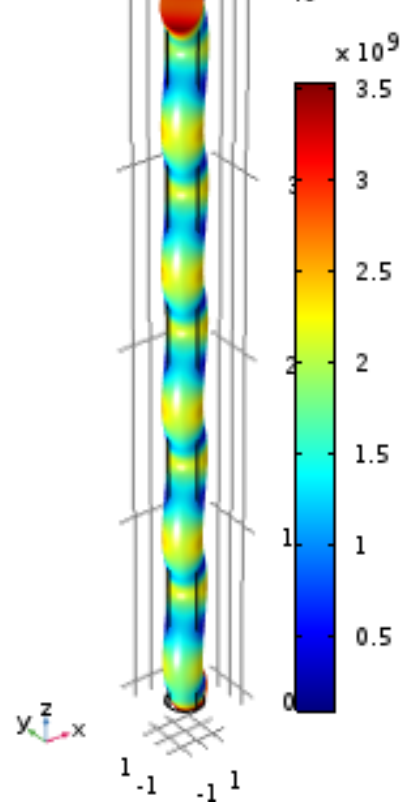

Mode 36 


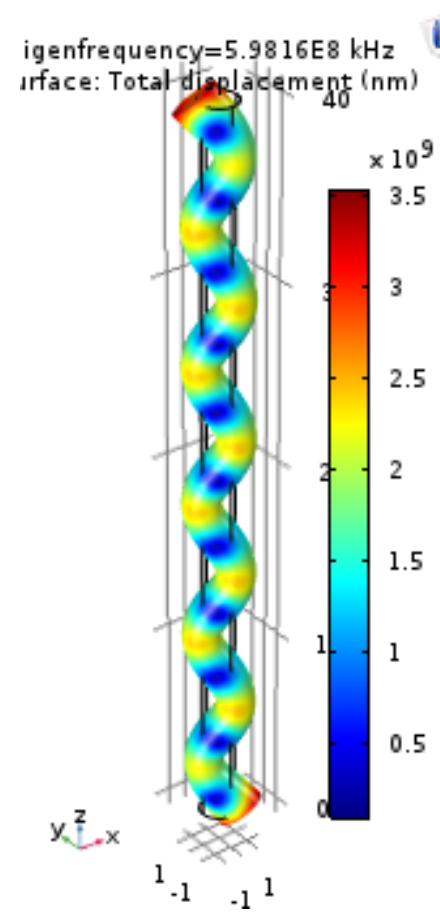

Mode 37

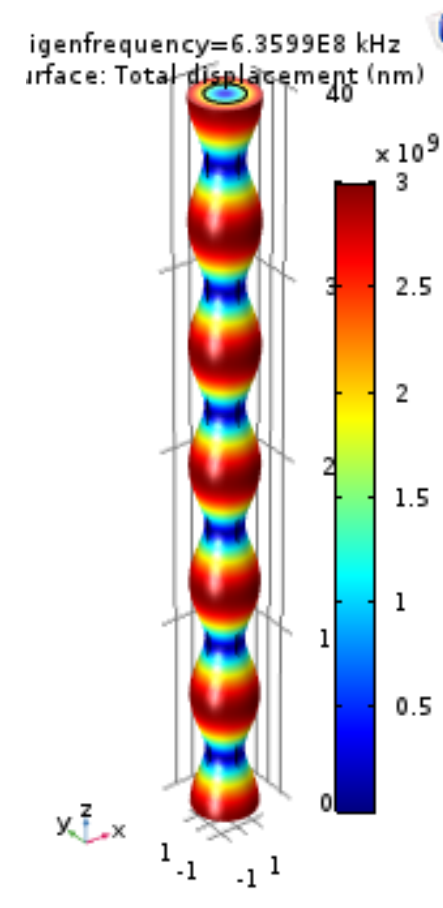

Mode 38

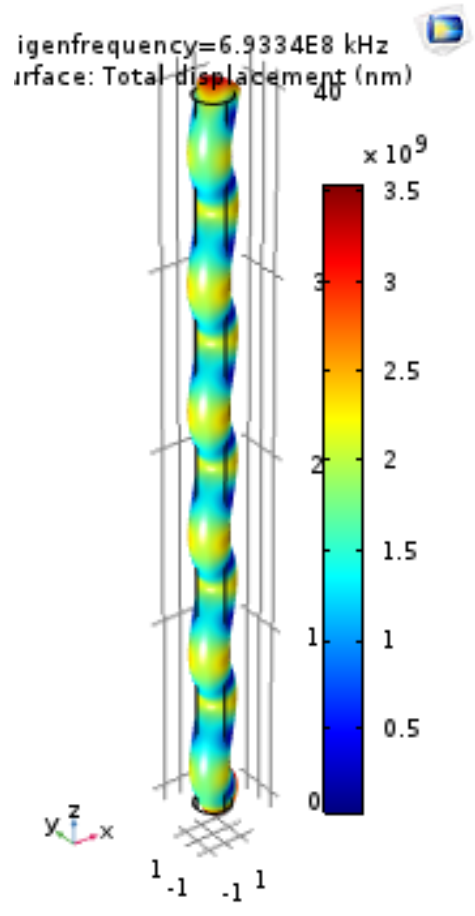

Mode 39

Fig. 2. First thirty-nine modes of SiCNW

The aim of the analysis is to obtain first ten eigenfrequency values and mode shapes of silicon carbide nanowire (SiCNW). First thirty-nine modes of SiCNW is calculated and results are demonstrated in Fig. 2. The cause to calculating thirty-nine modes is to obtain the proper first ten modal analysis results. As it can be clearly seen from Fig. 2, mode number calculated by the software include symmetrical modes and undesirable distensions modes. To overcome this issue, first ten mode numbers need to be selected carefully from thirty-nine mode shapes.

Sifting mode shapes can be easily done by visual choosing in current software. Familiar mode shapes can be easily differed from others while symmetric shapes need some more attention. In Fig. 3, selected and intended analyzes results is demonstrated with related eigenfrequencies. 


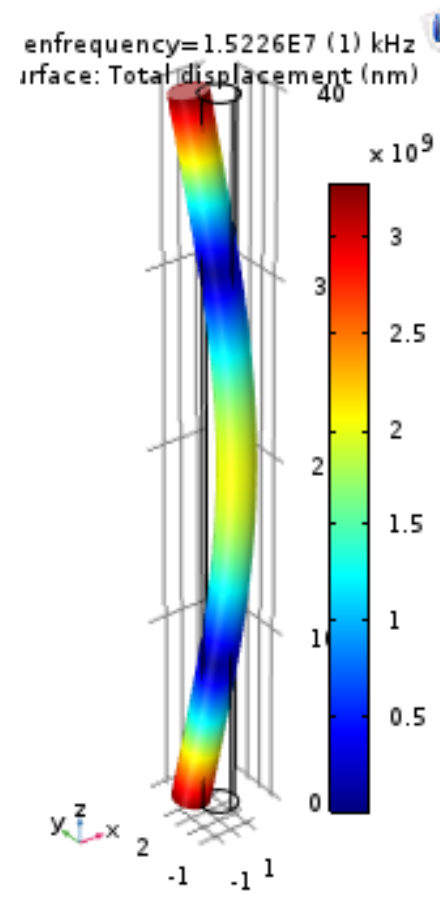

Mode 1

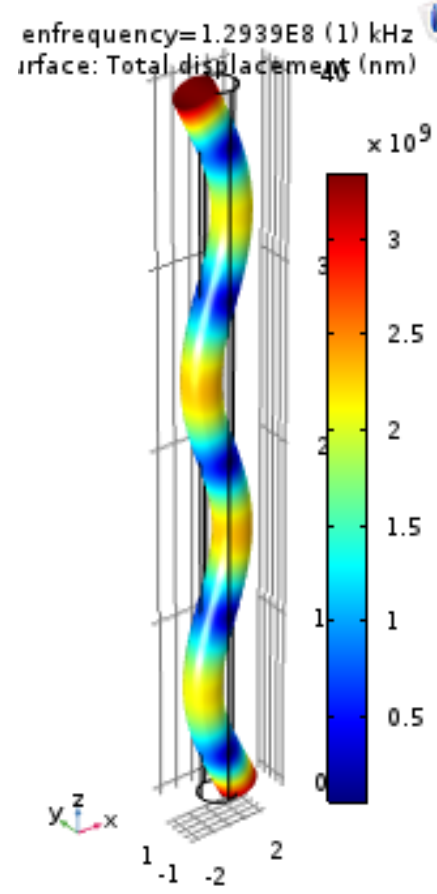

Mode 4

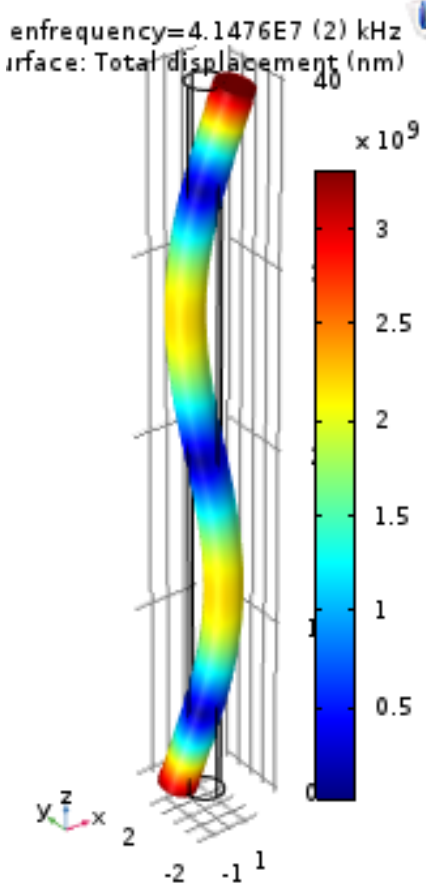

Mode 2 enfrequency $=7.995667(2) \mathrm{kHz}$
Ifface: Total.displacememe $45(\mathrm{~nm})$

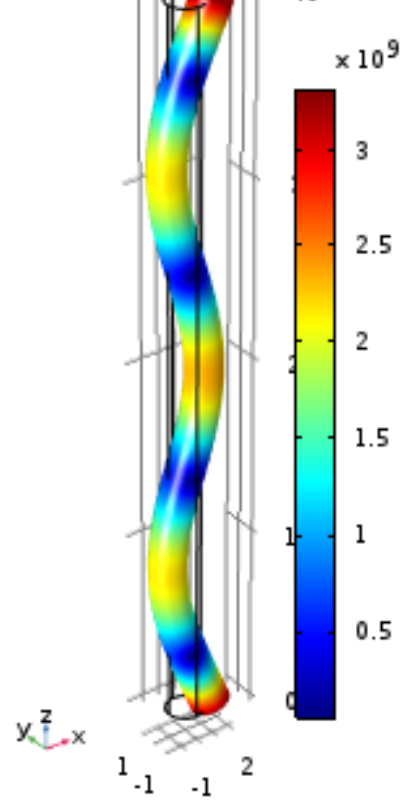

Mode 3

\section{$\square$}

enfrequency $=1.8852 \mathrm{E} 8$ (1) $\mathrm{kHz}$ Ifface: Total distalackement $(\mathrm{nm})$

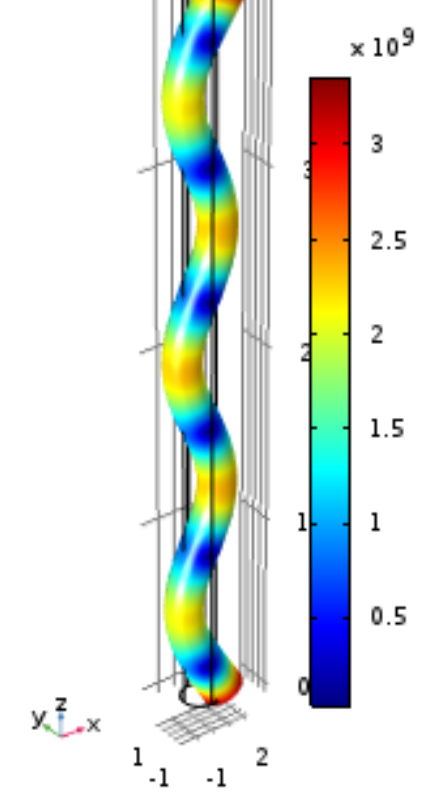

Mode 5

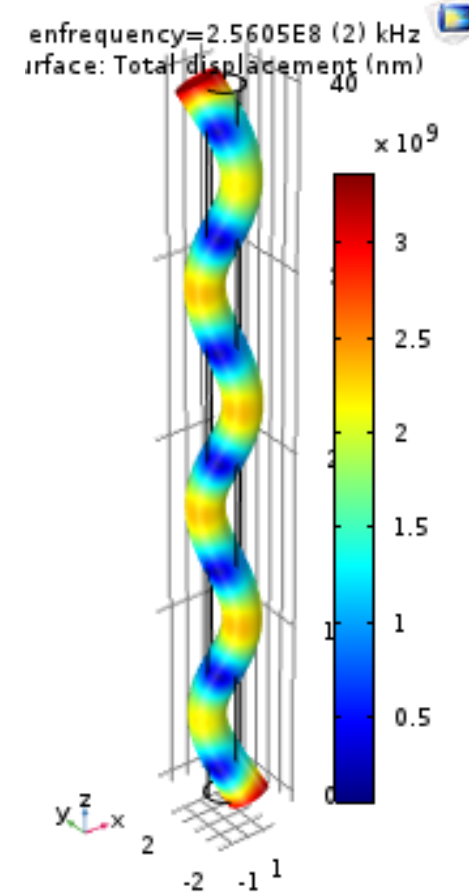

Mode 6 


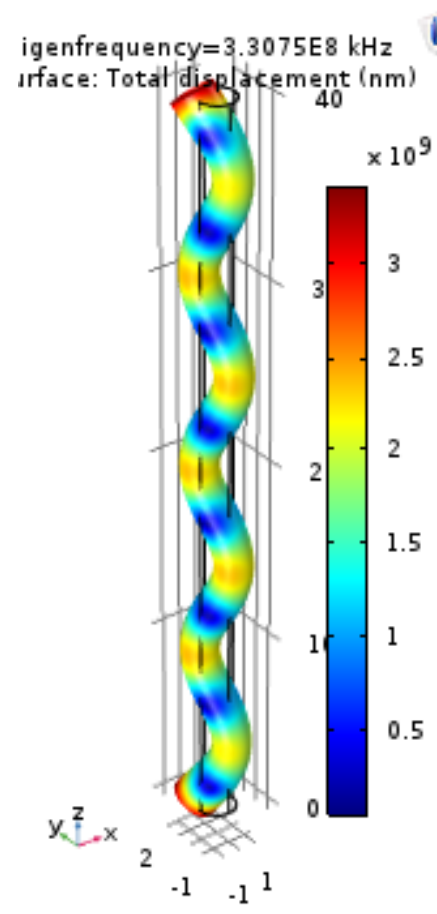

Mode 7

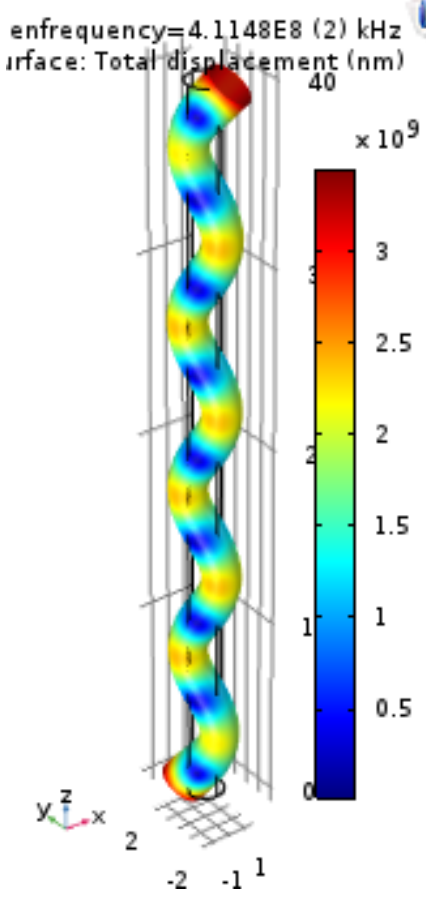

Mode 8

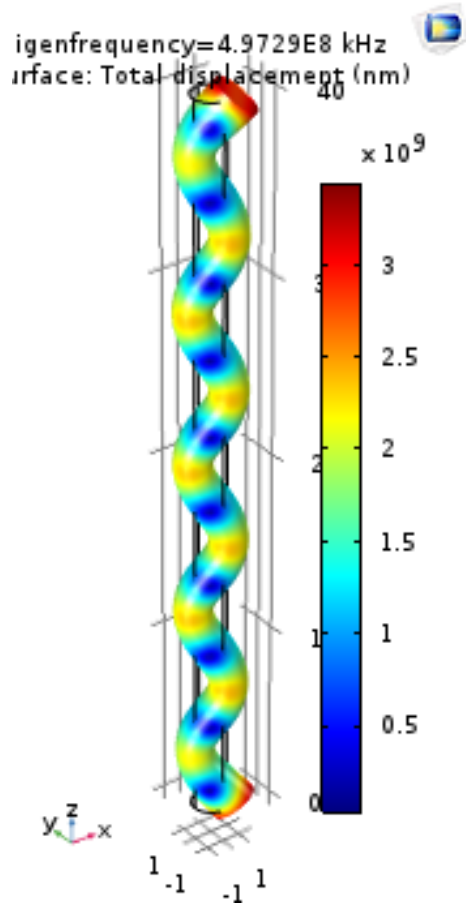

Mode 9

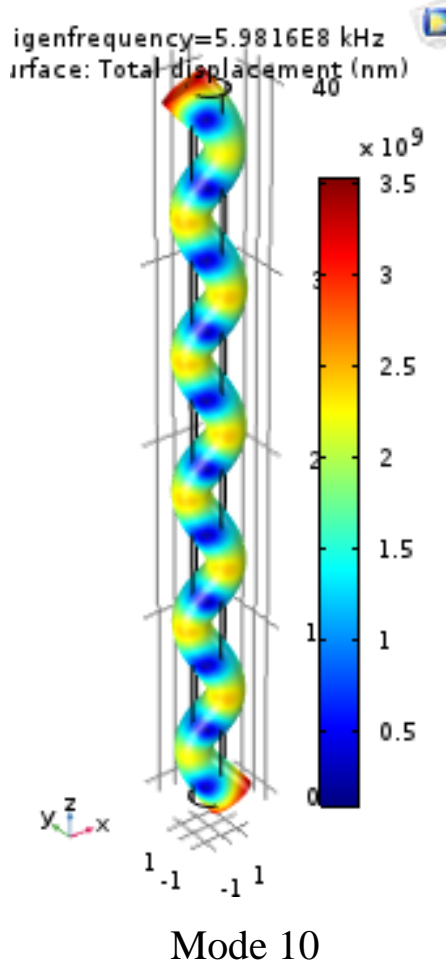

Fig. 3. Sifted first ten modes of SiCNW 


\section{Conclusions}

In present study, the modal analysis of SiCNW is investigated using COMSOL Multiphysics computer software. Also, the right way of meshing and preparing micro and nano sized structures is demonstrated. To obtain intended first ten modes of SiCNW, thirty-nine modes needed to be calculated. After calculating mode shapes, results are sifted and desired first ten mode shapes are illustrated with related eigenfrequency value. This is a paper to give the introduction to finite element analysis softwares in micro and nano sizes. The future works can be comparing these results with size effective theories and see the validation of size effective constants.

\section{Acknowledgements}

The financial support of the scientific research projects unit of Akdeniz University is gratefully acknowledged.

\section{References}

[1] Civalek, Ö., Demir, C., Buckling and bending analyses of cantilever carbon nanotubes using the euler-bernoulli beam theory based on non-local continuum model. Asian Journal of Civil Engineering, 12(5), 651-661, 2011.

[2] Emsen, E., Mercan, K., Akgöz, B., Civalek, Ö., Modal analysis of tapered beam-column embedded in Winkler elastic foundation. International Journal of Engineering \& Applied Sciences, 7(1), 1-11, 2015.

[3] Demir, Ç., Akgöz, B., Erdinç, M.C., Mercan, K., Civalek, Ö., Elastik bir ortamdaki grafen tabakanın titreşim hesabı. Gazi Üniversitesi Mühendislik-Mimarlık Fakültesi Dergisi, 32(2), 2017.

[4] Demir, C., Mercan, K., Numanoglu, H.M., Civalek, O., Bending response of nanobeams resting on elastic foundation. Journal of Applied and Computational Mechanics, 4(2), 105114, 2018.

[5] Mercan, K., Civalek, Ö., Buckling analysis of silicon carbide nanotubes (SiCNTs). International Journal of Engineering \& Applied Sciences, 8(2), 101-108, 2016.

[6] Avcar, M., Effects of rotary inertia shear deformation and non-homogeneity on frequencies of beam. Structural Engineering and Mechanics, 55(4), 871-884, 2015.

[7] Avcar, M., Effects of Material Non-Homogeneity and Two Parameter Elastic Foundation on Fundamental Frequency Parameters of Timoshenko Beams. Acta Physica Polonica A, 130(1), 375-378, 2016.

[8] Avcar, M., Mohammed, W.K.M., Free vibration of functionally graded beams resting on Winkler-Pasternak foundation. Arabian Journal of Geosciences, 11(10), 2018. 
[9] Aktir, Y., Brunel, J.F., Dufrenoy, P., Mahe, H., Three-dimensional finite element model of an automotive clutch for analysis of axial vibrations. Proceedings of the Institution of Mechanical Engineers Part D-Journal of Automobile Engineering, 230(10), 1324-1337, 2016.

[10] Kim, B., Finite Element Modeling and Parametric Study of an Automotive V-belt Pulley for Durability Improvement. International Journal of Precision Engineering and Manufacturing, 16(7), 1517-1524, 2015.

[11] Kim, H.Y., Park, J.K., Lee, M.G., Phase transformation-based finite element modeling to predict strength and deformation of press-hardened tubular automotive part. International Journal of Advanced Manufacturing Technology, 70(9-12), 1787-1801, 2014.

[12] Le Henaff, F., Azzopardi, S., Woirgard, E., Youssef, T., Bontemps, S., Joguet, J., Lifetime Evaluation of Nanoscale Silver Sintered Power Modules for Automotive Application Based on Experiments and Finite-Element Modeling. Ieee Transactions on Device and Materials Reliability, 15(3), 326-334, 2015.

[13] Pisaturo, M., Senatore, A., Simulation of engagement control in automotive dry-clutch and temperature field analysis through finite element model. Applied Thermal Engineering, 93, 958-966, 2016.

[14] Toros, S., Altinel, K., Contribution of functionally graded material modelling on finite element simulation of rod end parts in automotive steering system. Journal of Mechanical Science and Technology, 30(7), 3137-3141, 2016.

[15] Wong, P.K., Xie, Z.C., Zhao, J., Xu, T., He, F., Analysis of automotive rolling lobe air spring under alternative factors with finite element model. Journal of Mechanical Science and Technology, 28(12), 5069-5081, 2014.

[16] Civalek, Ö., Geometrically non-linear static and dynamic analysis of plates and shells resting on elastic foundation by the method of polynomial differential quadrature (PDQ). 2004, Elazig: Firat University.

[17] Civalek, O., Finite Element analysis of plates and shells. 1998, Elazığ: Firat University

[18] Civalek, O., Demir, C., A simple mathematical model of microtubules surrounded by an elastic matrix by nonlocal finite element method. Applied Mathematics and Computation, 289, 335-352, 2016.

[19] Jian, F.J., Jayas, D.S., Characterization of isotherms and thin-layer drying of red kidney beans, Part II: Three-dimensional finite element models to estimate transient mass and heat transfer coefficients and water diffusivity. Drying Technology, 36(14), 1707-1718, 2018.

[20] Mu, L.Z., Shao, H.W., He, Y., Oda, T., Jia, X.M., Construction of Anatomically Accurate Finite Element Models of the Human Hand and a Rat Kidney. Journal of Mechanics in Medicine and Biology, 11(5), 1141-1164, 2011.

[21] Snedeker, J.G., Bajka, M., Hug, J.M., Szekely, G., Niederer, P., The creation of a highfidelity finite element model of the kidney for use in trauma research. Journal of Visualization and Computer Animation, 13(1), 53-64, 2002. 
[22] Yates, K.M., Untaroiu, C.D., Finite element modeling of the human kidney for probabilistic occupant models: Statistical shape analysis and mesh morphing. Journal of Biomechanics, 74, 50-56, 2018.

[23] Das, A.K., Chatterjee, S., Finite element method-based modelling of flow rate and temperature distribution in an oil-filled disc-type winding transformer using COMSOL multiphysics. Iet Electric Power Applications, 11(4), 664-673, 2017.

[24] AB, w.c.c.C., COMSOL Multiphysics ${ }^{\circledR}$. 2018: Stockholm, Sweden.

[25] Mercan, K., Civalek, O., Buckling analysis of Silicon carbide nanotubes (SiCNTs) with surface effect and nonlocal elasticity using the method of HDQ. Composites Part BEngineering, 114, 35-45, 2017.

[26] Mercan, K., Numanoglu, H.M., Akgoz, B., Demir, C., Civalek, O., Higher-order continuum theories for buckling response of silicon carbide nanowires (SiCNWs) on elastic matrix. Archive of Applied Mechanics, 87(11), 1797-1814, 2017. 